\title{
Starfish and horseshoe crab egg factors cause elevations of cyclic nucleotide concentrations in spermatozoa from starfish and horseshoe crabs
}

\author{
D. Janette Tubb, G. S. Kopf and D. L. Garbers \\ Departments of Pharmacology and Physiology, Vanderbilt University, School of Medicine, \\ Nashville, Tennessee 37232, U.S.A.
}

\begin{abstract}
Summary. Factors collected from the eggs of the starfish (Pisaster giganteus) and the horsehoe crab (Limulus polyphemus) caused significant increases in the sperm cyclic nucleotide concentrations of the respective species. Sea urchin egg factors, at concentrations that resulted in maximal cyclic nucleotide elevations in sea urchin spermatozoa, had no effect on those of starfish or horseshoe crab, suggesting a species specificity with respect to egg factor-induced changes in sperm cyclic nucleotide metabolism.
\end{abstract}

\section{Introduction}

Substances which affect cyclic nucleotide metabolism of sea urchin spermatozoa have been found to be associated with sea urchin eggs (Garbers \& Hardman, 1975, 1976). Within 0.5 min, these egg factors caused up to 100 -fold increases in the cyclic AMP concentrations of Strongylocentrotus purpuratus spermatozoa, while cyclic GMP concentrations were either depressed or not affected (Garbers \& Hardman, 1975, 1976). $\mathrm{Ca}^{2+}$ is absolutely required to observe these egg factor-induced elevations of sperm cyclic AMP concentrations in simulated seawater at pH 7.9 (Tubb, Kopf \& Garbers, 1978). In the present studies we investigated whether the eggs from one species of starfish and the horseshoe crab have factors associated with them that can significantly elevate starfish or horseshoe crab sperm cyclic AMP concentrations.

\section{Materials and Methods}

The starfish (Pisaster giganteus) were obtained from Pacific Biomarine (Venice, California) and the horseshoe crabs (Limulus polyphemus) were from Marine Biologicals (Woods Hole, Massachusetts).

Dissected, intact starfish gonads were placed in a small amount of $\mathrm{Ca}^{2+}$-free seawater and minced to release the eggs or spermatozoa. The suspensions were filtered through cheesecloth to remove tissue debris, and then washed as described previously (Garbers \& Hardman, 1975, 1976) except that in some experiments $\mathrm{Ca}^{2+}$-free seawater was substituted for normal seawater when washing the spermatozoa. Eggs and spermatozoa were obtained from horseshoe crabs by applying gentle pressure on the area surrounding the genital pore. The spermatozoa were collected with a Pasteur pipette and the eggs were removed with a spatula. Factors released from eggs (FRE) were obtained by allowing the eggs of each species to stand in normal seawater for $1-2 \mathrm{~h}$, and then collecting the fluid above the eggs by low-speed centrifugation. $\mathrm{Ca}^{2+}$-free egg factors were prepared by extensive dialysis against $\mathrm{Ca}^{2+}$-free seawater. Incubations using starfish and horseshoe crab spermatozoa were initiated by the addition of washed spermatozoa (10- 
$20 \mathrm{mg}$ wet wt) to tubes containing theophylline $(1.5 \mathrm{mM})$ and/or FRE (100 or $400 \mu \mathrm{l})$ in the presence or absence of $7.7 \mathrm{mM}^{-\mathrm{Ca}^{2+}}$. Incubation times were as indicated in the 'Results'. After termination of the incubations, cyclic AMP and cyclic GMP concentrations were estimated as described elsewhere (Garbers \& Hardman, 1975, 1976).

\section{Results and Discussion}

Basal concentrations of cyclic AMP in starfish spermatozoa were between 5 and $7 \mathrm{nmol} / \mathrm{g}$ wet wt cells (Table 1). These concentrations are about twice those observed in sea urchin spermatozoa (Garbers \& Hardman, 1975, 1976). Cyclic GMP concentrations were about 10\% of the basal cyclic AMP concentrations. Theophylline $(1.5 \mathrm{~mm})$ caused a small increase in cyclic nucleotide concentrations and starfish FRE alone had little, if any, effect (Table 1). However, starfish FRE

Table 1. The effect of starfish and sea urchin egg factors on cyclic nucleotide concentrations (nmol/g wet wt cells) of starfish spermatozoa

\begin{tabular}{|c|c|c|c|c|c|c|c|}
\hline \multirow{2}{*}{$\begin{array}{l}\text { Egg factor } \\
\text { addition }\end{array}$} & \multirow{2}{*}{$\begin{array}{l}\text { Theophylline } \\
\text { (1.5 mM) }\end{array}$} & \multicolumn{3}{|c|}{ Cyclic AMP } & \multicolumn{3}{|c|}{ Cyclic GMP } \\
\hline & & $0.5 \mathrm{~min}$ & $2 \mathrm{~min}$ & $10 \mathrm{~min}$ & $0.5 \mathrm{~min}$ & $2 \min$ & $10 \mathrm{~min}$ \\
\hline None & $\overline{+}$ & $\begin{array}{r}6.9 \pm 0.4 \\
10.7 \pm 0.3\end{array}$ & $\begin{array}{l}6.1 \pm 0.2 \\
8.2 \pm 0.2\end{array}$ & $\begin{array}{l}5.6 \pm 0.2 \\
6.7 \pm 0.2\end{array}$ & $\begin{array}{l}0.42 \pm 0.03 \\
0.56 \pm 0.02\end{array}$ & $\begin{array}{l}0.56 \pm 0.08 \\
0.57 \pm 0.07\end{array}$ & $\begin{array}{l}0.36 \pm 0.05 \\
0.38 \pm 0.02\end{array}$ \\
\hline Starfish & $\overline{+}$ & $\begin{array}{r}7.3 \pm 0.1 \\
14.3 \pm 0.2\end{array}$ & $\begin{array}{r}6 \cdot 7 \pm 0.1 \\
13.9 \pm 0.9\end{array}$ & $\begin{array}{l}5.6 \pm 0.2 \\
7.4 \pm 0.2\end{array}$ & $\begin{array}{l}0.41 \pm 0.02 \\
0.92 \pm 0.02\end{array}$ & $\begin{array}{l}0.48 \pm 0.06 \\
0.93 \pm 0.09\end{array}$ & $\begin{array}{l}0.25 \pm 0.01 \\
0.31 \pm 0.02\end{array}$ \\
\hline Sea urchin & - & $\begin{array}{r}6.9 \pm 0.4 \\
10.3 \pm 0.2\end{array}$ & $\begin{array}{l}6.4 \pm 0.4 \\
8.6 \pm 0.3\end{array}$ & $\begin{array}{l}5.3 \pm 0.3 \\
6.2 \pm 0.2\end{array}$ & $\begin{array}{l}0.40 \pm 0.03 \\
0.46 \pm 0.04\end{array}$ & $\begin{array}{l}0.52 \pm 0.06 \\
0.65 \pm 0.06\end{array}$ & $\begin{array}{l}0.27 \pm 0.01 \\
0.39 \pm 0.01\end{array}$ \\
\hline
\end{tabular}

The values represent the mean \pm s.e.m. of 12 observations.

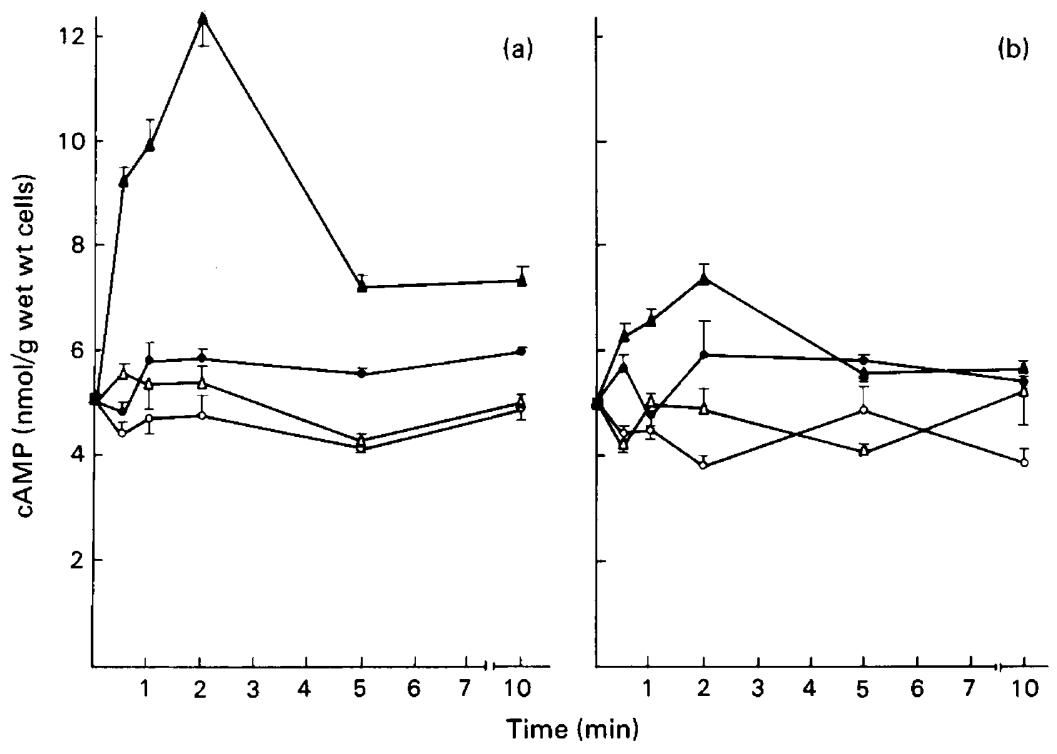

Text-fig. 1. The effects of starfish egg factors on starfish sperm cyclic AMP concentrations in the presence (a) $7.7 \mathrm{~mm}$ or absence (b) of $\mathrm{Ca}^{2+}$. The values presented represent the mean \pm s.e.m. of 4 individual observations. $\triangle$, FRE +1.5 mM-theophylline; $\triangle$, FRE; $0,1.5 \mathrm{mM}^{-}$ theophylline; $O$, control. 
+ theophylline caused significant increases in sperm cyclic AMP and cyclic GMP concentrations (Table 1); these effects, which were maximal at $0.5 \mathrm{~min}$, had essentially disappeared after incubation with the factor for $10 \mathrm{~min}$. The elevation of cyclic AMP in starfish spermatozoa was considerably less than that observed in sea urchins (Garbers \& Hardman, 1975, 1976), but was consistently observed in all experiments. The FRE from sea urchins, at concentrations which cause up to 100-fold elevations in sea urchin sperm cyclic AMP, failed to have any effect on cyclic nucleotide concentrations in starfish spermatozoa (Table 1).

Since $\mathrm{Ca}^{2+}$ is absolutely required for the action of sea urchin FRE, the effect of starfish FRE on cyclic AMP concentrations in the presence or absence of $\mathrm{Ca}^{2+}$ was evaluated. As shown in Text-fig. 1 starfish FRE failed to elevate sperm cyclic AMP concentrations in the absence of $\mathrm{Ca}^{2+}$ at any of the times chosen, indicating the necessity for $\mathrm{Ca}^{2+}$ in the action of FRE in this species also.

Spermatozoa of the horseshoe crab were completely immotile in the absence of added FRE of horseshoe crabs. Upon addition of horseshoe crab FRE, the spermatozoa immediately became very motile. Cyclic AMP concentrations in horseshoe crab spermatozoa were very high (6-7 $\mathrm{nmol} / \mathrm{g}$ wet wt cells), but cyclic GMP concentrations were extremely low $(2-3 \mathrm{pmol} / \mathrm{g}$ wet wt cells). The addition of horseshoe crab FRE to the spermatozoa caused a marked increase in

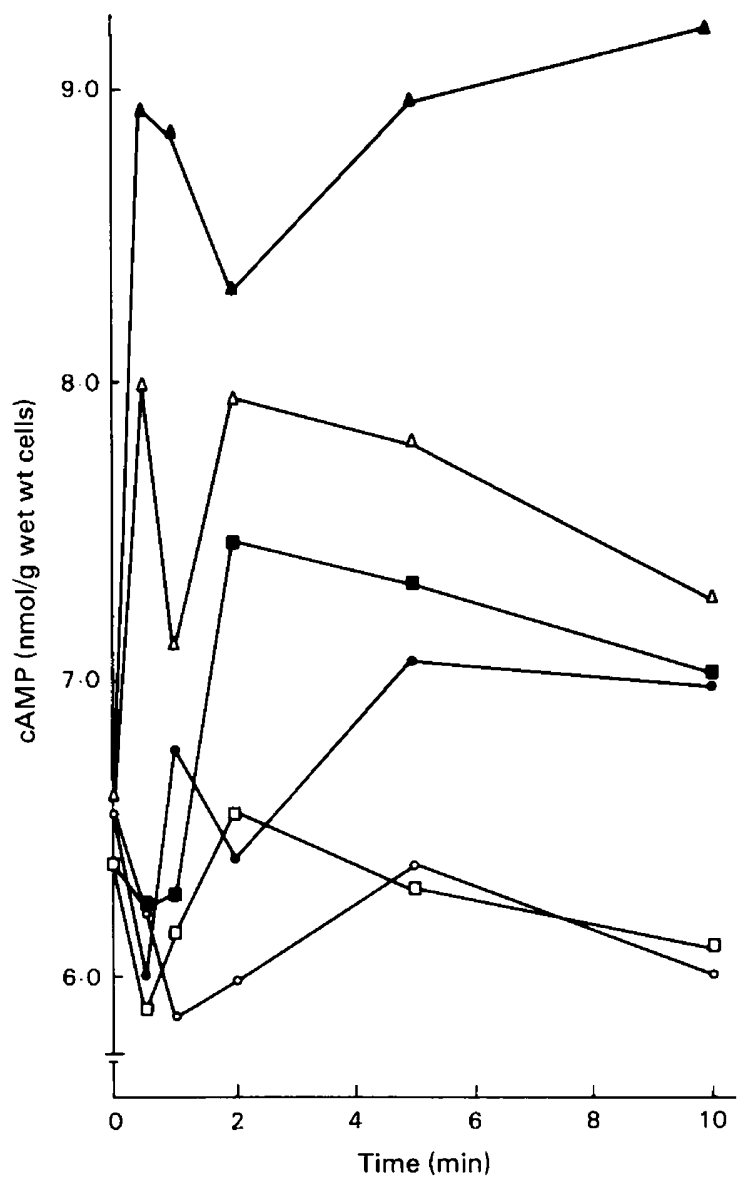

Text-fig. 2. The effects of horseshoe crab and sea urchin egg factors $(100 \mu l)$ on horseshoe crab spermatozoa. The values represent the means of 4 observations. $\triangle$, Horseshoe crab FRE +1.5 mM-theophylline; $\triangle$, horseshoe crab FRE; $\boldsymbol{\square}$, sea urchin FRE + 1.5 mM-theophylline; $\mathbf{0}, 1.5$ mM-theophylline; $\square$, sea urchin FRE; O, control (no additions). 
cyclic AMP concentrations within $\mathbf{0 . 5} \mathrm{min}$ in the presence or absence of theophylline (Text-fig. 2). Cyclic GMP concentrations did not appear to be increased by horseshoe crab FRE (data not shown), and the addition of sea urchin FRE failed to have any effect on cyclic AMP or cyclic GMP concentrations of horseshoe crab spermatozoa.

These data represent the first demonstration of species specificity with respect to FREinduced sperm cyclic AMP elevations, and suggest that specific sperm receptors interact with specific egg factor(s).

Work supported by NIH grants HD 10254 and HD 05797.

\section{References}

Garbers, D.L. \& Hardman, J.G. (1975) Factors released from sea urchin eggs affect cyclic nucleotide metabolism in sperm. Nature, Lond. 257, 677-678.

Garbers, D.L. \& Hardman, J.G. (1976) Effects of egg factors on cyclic nucleotide metabolism in sea urchin sperm. J. cyclic Nuc. Res. 2, 59-70.

Tubb, D.J., Kopf, G.S. \& Garbers, D.L. (1978) The elevation of sperm adenosine $3^{\prime}, 5^{\prime}$-monophosphate concentrations by factors released from eggs requires calcium. Biol. Reprod. 18, 181-185.

Received 14 October 1978 